\title{
Research on control system of truck-mounted rig for coalbed methane
}

\author{
Hejian Wang, Dong Fan, Yinsheng Weng \\ Xi'an Research Institute of China Coal Technology \& Engineering Group Corp, Xi'an, Shaanxi, China
}

\begin{abstract}
The coal-bed methane (CBM) as a kind energy is clean and efficient, also it can become a security risk in mining process if it could not get out of the coal seam. In view of the current large-scale exploitation of coal-bed methane resources, the development of drilling rig for CBM drilling is needed. The parameters and structures were introduced in the paper. The rig uses a highly integrated approach that integrates the required functions on the chassis of the vehicle to meet the needs of rapid installation and transportation. Drilling control system uses hydraulic control and electro-hydraulic control dual control mode, can achieve short-range and remote control operations. The control system include security circuits and electric control system. Through the field trial, it is shown that the rig can meet the construction of the majority of coalbed methane drilling in the country and the performance is stable and the operation is simple.
\end{abstract}

\section{Introduction}

Coal-bed methane (known as gas) is a kind of clean energy stored in coal seam. The development and utilization of coalbed methane resources can effectively solve the geological disasters caused by gas, and can increase the energy supply and reduce its pollution to the environment. Ground coalbed methane extraction is an effective way to solve the problem of coal mine safety by extracting the gas in the coal field through the ground drilling technology, reducing the coal content and providing the safety guarantee for the large-scale coal mining [1-2]. China's coalbed methane resources are enriched in the Qinshui Basin, with more mountainous and hilly areas. Coalbed methane development wells are scattered and the well site space is small, which is difficult to set drilling equipment. Truck-mounted CBM drilling rigs are designed and developed for specific drilling environments. The main working parts of the rig are integrated into the chassis of the vehicle, and the installation and transportation are very easy. This type of rig was mainly used in drilling wells traditionally, and in recent years it has been gradually applied to the construction of coalbed methane drainage [3-7]. These rigs process adaptability, high construction efficiency and small footprint, is widely used in the development of coalbed methane. At present, the development of ground coalbed methane in China is limited by the factors such as geological conditions and mining technology. Because the output of single well is low and the comprehensive economy is poor, the demand for cost-effective vehicle drilling rig is urgent. In recent years, some manufacturers through the introduction, digestion, absorption and reinnovation, have launched a variety of vehicle rigs, to meet the domestic CBM drilling construction. The 100t truck-mounted drilling rig was developed by Xi'an Research Institute of China Coal Science and Technology Group which has the capability of coalbed methane drilling.

\section{Drilling parameters and mechanical systems}

\subsection{Parameters}

Ground coalbed methane well is divided into two types of directional well development and straight well [8]. Directional well development comprehensive low cost, large output, which is widely used in coalbed methane development. Mud motor must be needed in directional drilling, so the drilling rig requires brake function. In view of the specific geological conditions and development factors of coalbed methane burial in China, the capacity of drilling rig is $2500 \mathrm{~m}$. The main technical parameters of the drilling rig are shown in Table 1:

Table 1. Main Parameters of ZMK5530TZJ100 Truckmounted Drilling Rig

\begin{tabular}{|c|c|c|c|c|}
\hline depth & Torque & speed & $\begin{array}{c}\text { Feeding } \\
\text { force }\end{array}$ & $\begin{array}{c}\text { Lifting } \\
\text { force }\end{array}$ \\
\hline $2500 \mathrm{~m}$ & $30000 \mathrm{Nm}$ & $120 \mathrm{r} / \mathrm{min}$ & $180 \mathrm{kN}$ & $1000 \mathrm{kN}$ \\
\hline
\end{tabular}

\subsection{Feeding device}

The mast is made of telescopic structure, with a transportation size of only $13.6 \mathrm{~m}$, providing a $15 \mathrm{~m}$ 
stroke. The telescopic mast is mainly composed of a feed cylinder, a primary feeding device and a secondary feeding device. The cylinder barrel is fixed by the pin to the secondary feeding device, the piston rod is fixed with the first stage, and the feeding cylinder can drive the primary feeding device to move along the guide rail on the secondary feeding device. The top head can be moved through the wire rope in the feeding device. The feeding speed is twice the cylinder to improve the efficiency of drilling. Lifting, unloading and drilling from the single and so on the operation process efficient and reliable. With active pressurization function, handling hole accident ability.

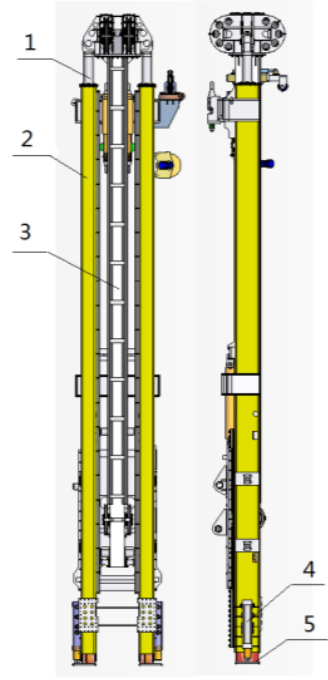

Figure 1. The structure of the feeding system.

1 -feed cylinder 2-Secondary feeding device 3-First feeding device 4-Mechanical outrigger 5-Solid device

\subsection{Top head}

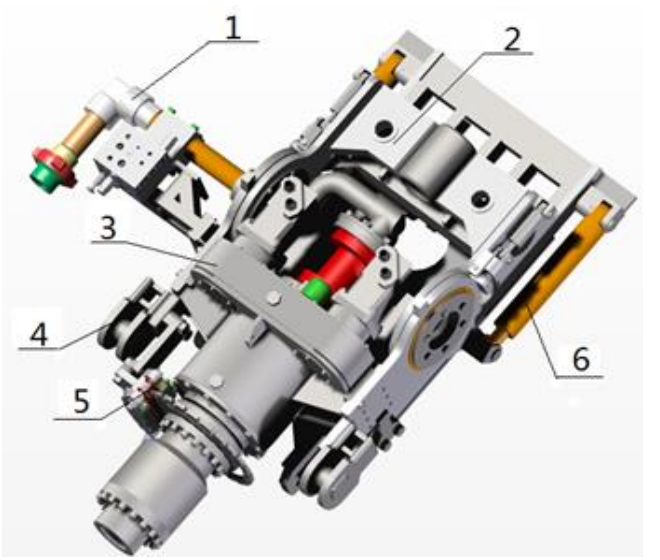

Figure 2. The structure of the Top head.

1 -mud pipes 2-pallet 3-rotation box 4-lug 5-brake 6angle tilting cylinder

Top head, also known as the top drive, is an important executive part of the rig. It is responsible for the hydraulic motor output speed and torque into a suitable parameter range and applied to the drill device. The top head can provide down pressure for the rig, reducing the dependence on the increased drill pipe at the beginning of the drilling. At the same time, in the event of an accident in the hole, you can provide additional pressure to improve the accident handling capacity. Top head (Figure 2) using four two-speed hydraulic motors with four small gears to drive a large gear in a gearbox, with a speed range of $0 \sim 120 \mathrm{r} / \mathrm{min}$., which can meet a variety of drilling needs. Top head through the brake device to achieve the spindle locking function to obtain accurate azimuth and slope, to achieve the bottom of the hole dynamic directional drilling, to meet the directional hole and branch hole construction. The diameter of spindle is up to $150 \mathrm{~mm}$, to meet the mud circulating, air circulation, air reverse circulation and gas lift reverse circulation and other drilling process.

\subsection{Power units}

Power units are the power source of the rig, made of a diesel oil tank, hydraulic oil tank, diesel engine and pump series. The diesel engine and the main pump are connected by an elastic clutch. In order to guarantee the normal work of the hydraulic system, the power units is equipped with many hydraulic accessories, such as oil filter, air cooler, air filter, oil temperature tester, liquid level indicator. Drill control system using electrohydraulic proportional control system which can achieve hydraulic control and remote electronic control dual control. The control system is the core of the full hydraulic rig, directly affects the overall performance and maneuverability of the rig. Drilling rigs need to control the action, including: top head rotation, quick feeding and pulling, slow feeding and pulling, clamp control, the main winch to enhance the laying, attitude adjustment, mast setting and landing, etc., .Torque adjustment, pressure control and other functions are also achieved. In order to ensure the safety of drilling, the system designed a variety of safety interlock protection circuit; important circuit are used multi-pump, multi-valve simultaneous control of the redundant design which had high reliability to prevent damage caused by a single hydraulic components. The display can monitor the running status of the diesel engine in real time and the drilling speed of the power head, torque, drilling.

\section{Control system}

\subsection{Hydraulic control system}

A drawing of the hydraulic control system is illustrated in Fig 3(a). The hydraulic system adopt open-type system, which provides the hydraulic oil to rotary and feed separately. The hydraulic system consists of 4 main pumps and 3 assistant pumps. This system is easy to control and repair. The speed control system is made up of variable pumps and four two-speed motors. The rotary speed of the motors can be adjusted according to practical conditions when drilling a borehole. The speed of motor can be adjusted within a certain range, so it improves the adaptability of drilling rig for different kinds of drilling technology. The drilling operation system controls the rig to carry out the drilling functions. The hydraulic system 
is a load-sensitive system and uses a hydraulic loadsensitive valve. The hydraulic control system is equipped with load sensing pumps and constant pressure pumps. The load sensing pump is used for the rotation of the top drive and fast moving of the mask. These controls feature load sensing and maximum pressure compensation. Load sense controls are used to match pump flow and pressure to system demands, thus minimizing losses due to wasted horsepower. The pump automatically adjusts for changes in drive speed and load pressures to match the pump output flow to the load requirement. Since the pump load sense control will maintain a constant pressure drop across the main system throttling valve, the flow rate will remain constant, independent of changes in load pressure and pump shaft speed. The data of load sensing pump is illustrated in Fig.3(b).

\section{load sensing and pressure limiter control}
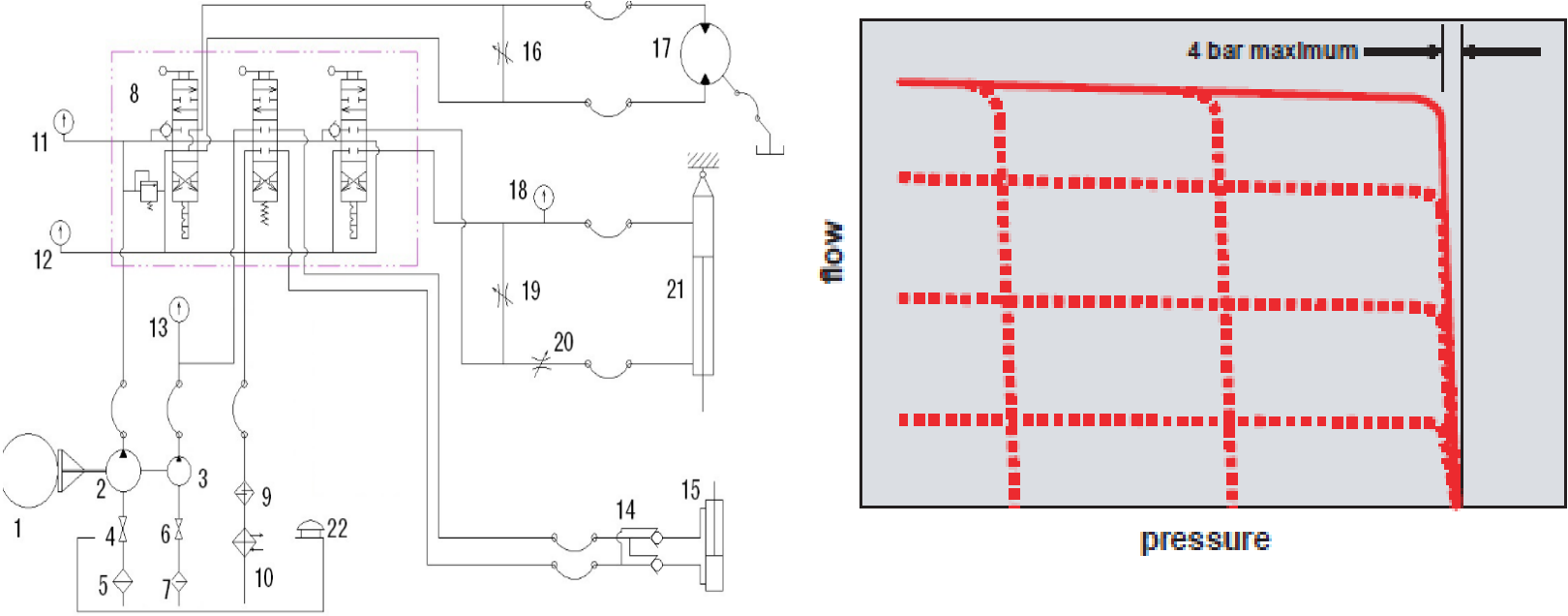

(b)

Figure 3. Hydraulic System Drawing and Load Sensing Pump Data.

\subsection{Diesel engine control system}

Hydraulic oil and diesel engine cooling control system as shown in Figure 4. The oil-return of hydraulic system can back to the air-cooled tank. Variable pump drive fan motor to cool the oil, radiator cooling capacity depends on motor speed. Hydraulic oil and diesel engine coolant circuit were set up on the temperature sensor, the electronic control system according to the temperature sensor temperature information on the solenoid valve issued a control signal, solenoid valve control variable pump displacement changes to change the fan motor speed. This control system allows the hydraulic system temperature from the environment, the system is always working in the best temperature range.

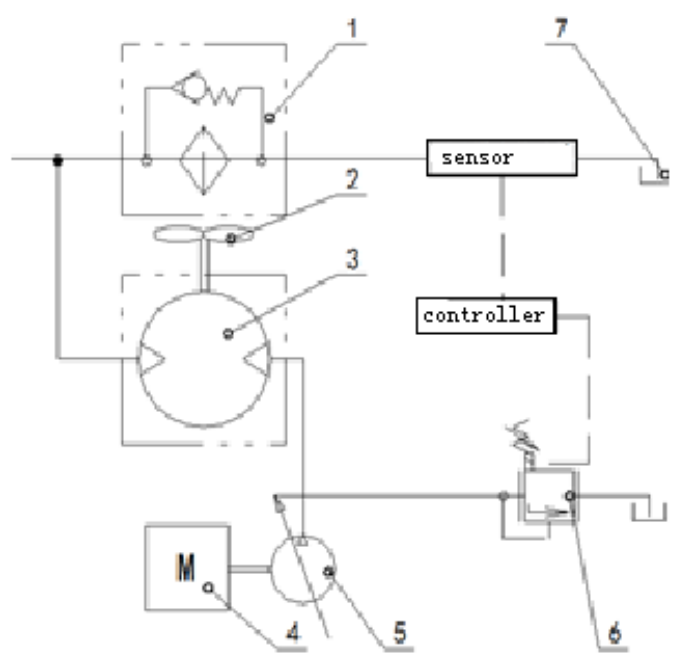

Figure 4. The closed-loops control system of temperature 1 -radiator 2 - cooling funs 3 - motor 4 - power unite 5

-variable motor; 6 - electric relief valves 7 - tank 


\subsection{Security circuits}

The reliable braking of the spindle is the guarantee of directional drilling. The pressure relief of the brake device will lead to the change of the angle of the mud motor. The pilot oil is used to prevent the pressure relief, and the pressure sensor is used to monitor the pressure change through the pressure sensor. Activated braking device will be damaged when the top head worked. In order to prevent misoperation, a new circuit was designed as shown in Figure 5, which is the spindle brake antirotation hydraulic principle circuit. The manual reversing valve controls the clamping and release of the brake, and the pressure sensor monitors the brake condition. When the brake device is clamped, the sensor detects that the pressure signal exceeds the set value, sends a signal from the controller, controls the electromagnetic directional valve commutation, cuts off the oil source of the pilot valve, and deactivates the hydraulic control valve of the operation top head. So as to avoid the braking device in the state of the power head forced rotation caused by the accident, improve the rig safety. The use of control pilot valve oil source on and off the principle of the design of the winch and power head anti-collision, winch arm and mast anti-collision and other security interlock protection circuit to avoid the accident caused by the accident, the system more secure and reliable.

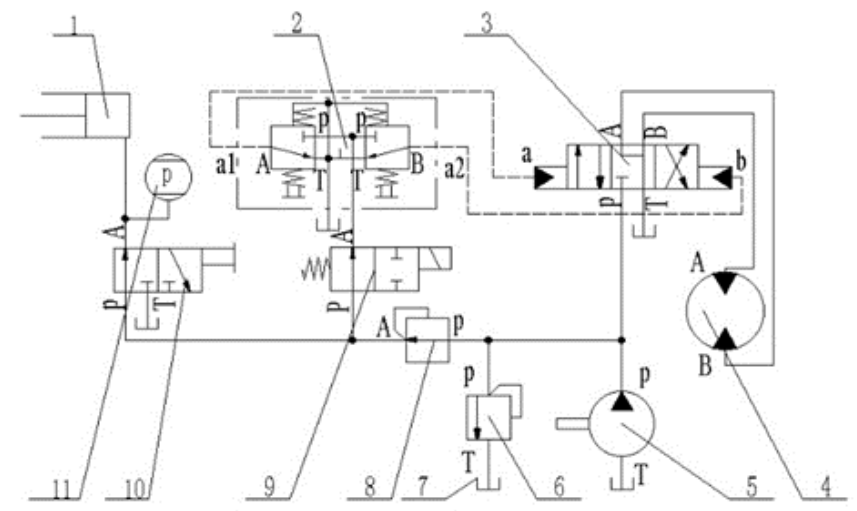

Figure 5. The hydraulic principle diagram with protection function

1 - brake 2-pilot valve 3-Hydraulic directional valve 4motor 5-pump 6-relief valve 7-tank 8-reducing valve 9electric directional valve 10 -manual directional valve $11-$ pressure sensor 12 - controller

\subsection{Operating system}

Drilling machine operating system using short-range hydraulic control and remote electro-hydraulic control in two ways. Remote operating control panel is shown in figure 6 . The main valve body are arranged in the rig body platform, the control valve is arranged in a separate control box. The hydraulic control console is arranged on the rear side of the vehicle body, close to the working table, easy to observe the drilling situation. Remote electro-hydraulic console placed in a separate control room, can be controlled within 50 meters, the use of wireless signal transmission. In the environmental conditions are good when using short-range console operations, harsh environment using remote console operations.

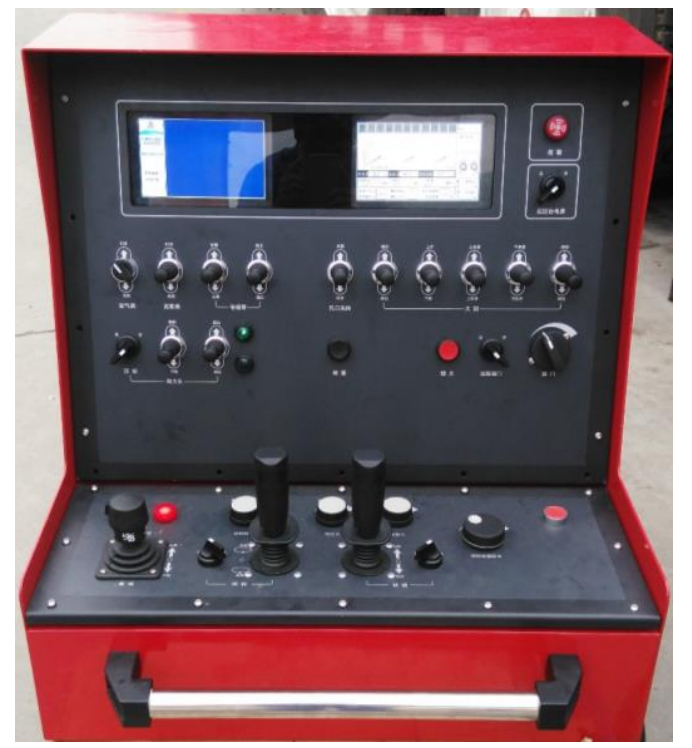

Figure 6. Remote operating control panel.

\subsection{Electric Control System}

All controls are conveniently located for easy operation. The control system structure is shown in Fig.7. The signal of analogue sensor is treated by signal adjustment circuit, the signal of digital sensor is isolated form ARM by high speed optoelectronic isolator, the switch of the switch joystick is treated directly by ARM, the signal of the joystick with potentiometer is enlarged by amplifier circuit. ARM outputs digit to FET driver circuit to drive switch electromagnetic valve, and outputs PWM to proportional amplifier circuit to drive proportional electromagnetic valve. The communication interface is CAN2.0 by CAN transceiver 82C251[9-20] and the system is communicated with outside by zigbee wireless and exchanges data between zigbee wireless chip and ARM by SPI bus inside. HMI is developed by LCM. 


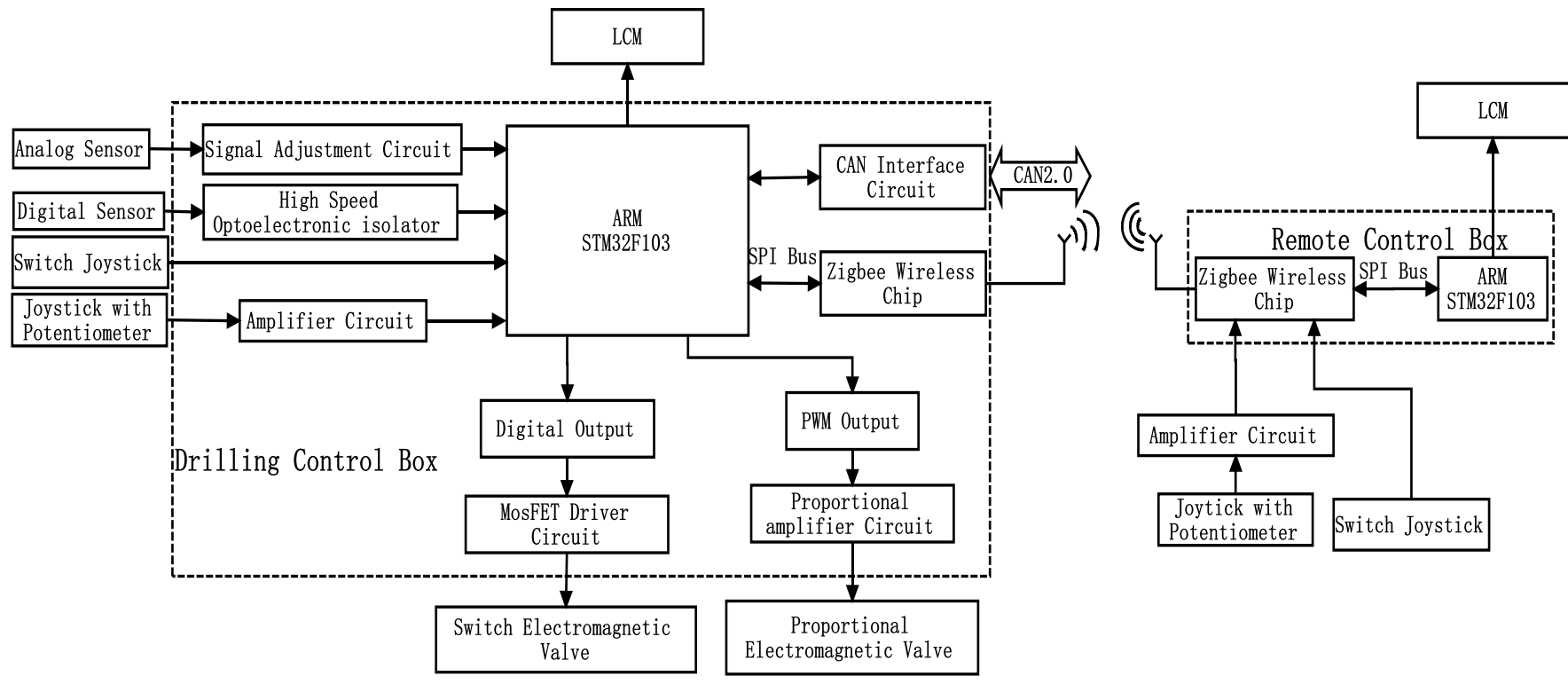

Figure 7. Electric Control System Structure.

\section{Field trial}

The Verification machine was tested to develop coalbed methane wells in Sihe District, Shanxi Province. The target coal seam was 3 \# coal seam. The average thickness of the coal seam was $6.25 \mathrm{~m}$. Ordinary straight wells cannot fully cover the pre-pumping area for the reasons of high dense CBM, affecting the safety of coal production and mining convergence. In order to solve the above problems and achieve rapid reduction of gas content, a horizontal hole was need to be drilled to ensure the safety of coal production purposes, the structure of the horizontal hole is shown in Figure 8 . The test site is located above the hills and the road is narrow. Part of the road is not hardened, the slope of more than $25^{\circ}$, the rig get through the test and the climbing ability and mobility were verified. The DTH drilling technology, PDC rotary drilling technology, directional drilling technology were tested in the construction. To complete a depth of $1675 \mathrm{~m}$ horizontal directional hole, the performance and process adaptability were verified.

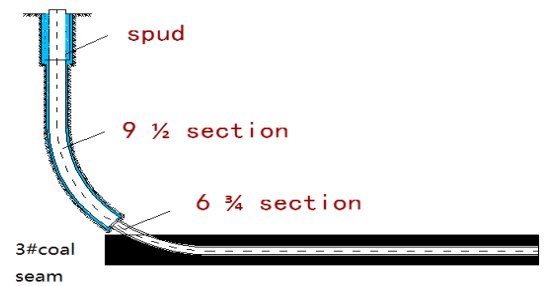

Figure 8. Structure of the horizontal hole.

\section{Conclusions}

The truck-mounted drilling rig adopts hydraulic drive, hydraulic control and electro-hydraulic control double control mode, to meet a variety of conditions construction requirements. The multiple protection circuit used in the control system effectively protects the safety of the equipment. Experiments show that the rig can meet the $2500 \mathrm{~m}$ coalbed methane resource mining requirements.

\section{Acknowledgement}

The work presented in this paper was financial supported by the Major Project of the National Science and Technology (No. 2016ZX05045001-002).

\section{References}

1. Hu Qianting, Sun Haitao, Du Zijian. Practices and application prospects on development engineering of Coal-bed methane surface well, Coal Science and Technology, 2015(9);59-64

2. LI Guo-fu, LI Gui-hong, LIU Gang. Analysis on the ground extraction effect of coal-bed methane at typical area in Jincheng, China, JOURNAL OF CHINA COAL SOCIETY, 2014,39(9):1932-1937.

3. Gao Hongliang. Application in geological exploration on truck-mounted drilling rig [J]. Equipment for Geotechnical Engineering. 2009(02):38-41

4. XU Liuwan, CAO Fude, GE Hewang. Current Situation of Application of Drilling Technology and Equipment for Hydrological Well, Exploration Engineering (Rock \& Soil Drilling and Tunneling) 2007,(01):37-42.

5. TIAN Hongliang, FAN Dong, CHANG Jianghua. Design of ZMK5530TZJ60 type Truck-mounted 
Drilling Rig. Technology and application of coal mine safety and high efficiency mining geology, China Coal Industry publishing House, 2014, 435440

6. Chen Yueqiang. Technology Analysis of The Domestic Rig Used in CBM [D]. Xi'an. Xi'an University of Science and Technology.

7. Yan Xuguang. Design and theoretical research on hoisting system of the slant CBM well rigs [D]. Xi'an. Xi'an Shiyou University

8. ZHANG Peihe, ZHANG Mingshan. Analysis of application status and adapting conditions for different methods of CBM development. COAL GEOLOGY \& EXPLORATION, 2010(4):9-13

9. Holger Kinzel. The Designing and Building of an All-Purpose Automatic Torque-Wrenching Machine for Drilling Rigs, IADC/SPE Drilling Conference, 02, 1992.

10. W.A. Hustrulid. Underground Mining Methods Handbook, 1982.

11. YIN Xin-shen. Application of load sensitive technology to mine roadway hydraulic driving head drilling rig, 01, 2008.

12. Parker. PD Series Axial Piston Pumps Variable Displacement, Catalog HY28-2663-01/NA,EU.
13. Yinsheng Weng. CAN Bus Communication System of Tunnel Drilling Rig in Coal Mine. Coal Mine Mechinery. 02, 2013.

14. 14.Tian Hongliang, Wang Hejian, Weng Yingsheng. Design of Track-mounted Drilling Rig Based on Wireless Remote Control System [C], ICMEE, 2013

15. ShueySA.Mining technology for the 21th century[C]:IncodigsdeepinSudbury[J].E\&MJChina, 1 992,2:7-11

16. KellyM. Developing coalmining technology for the 21th century $[\mathrm{C}] / /$ Proc Ming Sciand Tech, Rotterdam:AABalkema,1999

17. MichaelJ. Intelligent Drill Pipe Creates the Drilling Network SPE Asia Pacific Oil\&Gas Conference, 80454,2003

18. MichaelE,Reeves.IntelligentDrillStringFieldTrialsDe monstrateTechnologyFunctionalitySPE/IADCDrillin gConference, 92477,2005

19. TyberP.Controlling Cement Operationfroman Onshore Operation Center SPE/IADC Drilling Conference,92334,2005

20. LI Lin, Nurzat. Adaptive PID control strategy for the drilling-rig rotary system [J]. AC TA PET ROLEI SINICA.2011(1):158-161 